\title{
Potential of the association of dodecyl gallate with nanostructured lipid system as a treatment for paracoccidioidomycosis: In vitro and in vivo efficacy and toxicity
}

\author{
Junya de Lacorte Singulani $^{\mathrm{a}}$, Liliana Scorzoni ${ }^{\mathrm{a}}$, Natália Manuela Strohmayer Lourencetti ${ }^{\mathrm{a}}$, \\ Luana Rossi Oliveira ${ }^{a}$, Rosana Silva Conçolaro ${ }^{a}$, Patricia Bento da Silva ${ }^{a}$, Ana Carolina Nazaréb, \\ Carlos Roberto Polaquini ${ }^{\mathrm{b}}$, Francesca Damiani Victorelli ${ }^{\mathrm{a}}$, Marlus Chorilli ${ }^{\mathrm{a}}$, \\ Luis Octávio Regasini ${ }^{\mathrm{b}}$, Ana Marisa Fusco Almeida ${ }^{\mathrm{a}}$, Maria José Soares Mendes Giannini ${ }^{\mathrm{a}, *}$ \\ a São Paulo State University (UNESP), School of Pharmaceutical Sciences, Araraquara, São Paulo, Brazil \\ ${ }^{\text {b }}$ São Paulo State University (UNESP), Institute of Biosciences, Letters and Exact Sciences, São José do Rio Preto, São Paulo, Brazil
}

\section{A R T I C L E I N F O}

\section{Keywords:}

Paracoccidioides sp.

Antifungal compound

Lipid nanoparticles

In vivo models

Systemic mycosis

\begin{abstract}
A B S T R A C T
Paracoccidioidomycosis (PCM) is a systemic mycosis endemic in Latin America, caused by Paracoccidioides spp. A limited number of antifungal agents are available and the search for new compounds has increased. Additionally, nanostructured lipid system (NLS) has emmerged as an interesting strategy to carrier compounds for the treatment of mycosis. In this work, the antifungal efficacy and toxicity of dodecyl gallate (DOD) associated with a NLS was evaluated through in vitro and in vivo tests. DOD showed good in vitro antifungal activity and low toxicity in lung fibroblasts and zebrafish embryos, but no antifungal efficacy in infected mice, which may have been a result of low bioavailability. On the other hand, the association of DOD + NLS was beneficial and resulted in lower toxicity in lung fibroblasts and zebrafish embryos. In addition, NLS + DOD promoted a significant reduction in the fungal burden of mice lungs and could be a potential therapeutic option against PCM.
\end{abstract}

\section{Introduction}

Paracoccidioides brasiliensis and Paracoccidioides lutzii belong to the group of thermo-dimorphic fungi and cause paracoccidioidomycosis (PCM). This human systemic mycosis is endemic in Latin America, in which Brazil, Venezuela and Colombia are the countries with the highest number of cases (Bocca et al., 2013; Shikanai-Yasuda et al., 2006). The habitat of Paracoccidioides spp. can be the organic matter present in the soils, especially in areas of coffee and sugar cane cultivation (Arantes and Theodoro, 2016). The infection of these fungi occurs in mycelial form, which differentiates into yeast form after inhalation by the host. This transition is essential to establish the infectious process, in which the lung is the first site of infection and the yeasts can spread to other organs such as liver, spleen, mucous membranes, skin and central nervous system (Lacaz, 1994; Shikanai-Yasuda et al., 2006).

PCM requires prolonged treatment, which can occur for more than 1 year. Patients with this mycosis are commonly treated with amphotericin B (AmB), azoles and sulfonamides (Hahn et al., 2002). AmB is mainly used in severe cases of PCM and there are few instances of fungal resistance to this drug. The oral administration of this drug is not possible due to characteristics such as poor membrane permeability, low aqueous solubility, and instability at the low $\mathrm{pH}$ of the stomach (Mistro et al., 2012; Volmer et al., 2010). Thus, the conventional AmB (formulated in sodium deoxycholate) is administered intravenously and significant adverse effects may sometimes require the discontinuation of therapy. Injection usually results in chills, fever, tinnitus, headache, and vomiting. However, the most common and serious adverse effect is nephrotoxicity (Kauffman, 2006; Rang and Dale, 2007). A liposomal formulation was developed to minimize this effect, but the high cost has limited its use (Botero Aguirre and Restrepo Hamid, 2015). In addition, the use of new carrier systems such as poly (lactic-co-glycolic acid) nanoparticles, solid lipid nanoparticles (SLNs) and carbon nanotubes has been investigated (Benincasa et al., 2011; Chaudhari et al., 2016; Verma et al., 2011).

Azole, especially itraconazole, has been used in mild or moderate cases of PCM. Itraconazole is lipophilic and higher levels of this drug are found in different tissues and organs than serum, except in the cerebrospinal fluid, where the level of this antifungal is limited (Marwaha and Maheshwari, 1999). This class of drugs can be

\footnotetext{
* Corresponding author at: School of Pharmaceutical Sciences, São Paulo State University (UNESP), Rodovia Araraquara - Jaú Km 1, 14800-903 Araraquara, São Paulo, Brazil.

E-mail address: giannini@fcfar.unesp.br (M.J.S. Mendes Giannini).
} 
administered orally and have mild adverse effects (Rang and Dale, 2007). However, in addition to the inhibition of cytochrome P450 enzymes in fungi, azole inhibits the enzymes responsible for the hepatic metabolism of drugs in humans. As a consequence, azoles interact with various classes of antihistaminic, antineoplastic, steroid, antimicrobial, antiretroviral, opioid, barbiturate, cardiovascular, psychotropic and oral contraceptive drugs (Bates and Yu, 2003); moreover, they are teratogenic. In addition, Hahn et al. (2003) described the occurrence of ketoconazole resistant isolates of $P$. brasiliensis in patients with PCM. Since the similarity between fungal and mammalian cells makes the discovery and development of effective and safe antifungal agents a challenge, there are a limited number of antifungal agents and they present numerous disadvantages; in recent years, interest in the study of new compounds with antifungal potential and nanoparticle carriers for drugs and compounds has increased (Derengowski et al., 2009; Ostrosky-Zeichner et al., 2010; Petrikkos and Skiada, 2007; Scorzoni et al., 2017; Voltan et al., 2016).

Gallic acid is an example of a compound derived from secondary metabolism in several species of plants such as Paeonia rockii, Astronium sp., Syzygium cumini, Euphorbia lunulata, Labisia pumila, Zingiber officinale, Klainedoxa gabonensis, Nervilia aragoana, Atalantia monophylla, Lawsonia inermis, Ardisia chinensis and Alchornea glandulosa, which can be extracted from the leaves, stems, roots or fruits (Choubey et al., 2015; Santos et al., 2016). Previous studies showed that the gallic acid derivative, dodecyl gallate (DOD), presented in vitro activity against human fungal pathogens, including Candida spp, Cryptococcus gattii, Histoplasma capsulatum and Paracoccidioides sp. (de Paula e Silva et al., 2014). On the other hand, dodecyl gallate presents low solubility in water, which limits its parenteral administration and release in the bloodstream.

One strategy to increase drug stability and solubility and offer better bioavailability is the use of lipid nanoparticles, as for example, in the case of nanoemulsion for the antifungal itraconazole (Bunjes, 2010; Thakkar et al., 2015). Additionally, lipid nanoparticles could increase the therapeutic index of drugs and compounds by improving their activity and reducing their toxicity. Lipid-conjugated formulations of $\mathrm{AmB}$, for example, were approved in the 1990s and reduced the nephrotoxicity of the drug (Moen et al., 2009; Voltan et al., 2016). Lipid nanoparticles are widely used for various routes of administration including parenteral due to their excellent biocompatibility and low toxicity. Because of these reasons, we evaluated and characterized the association of the DOD in a nanostructured lipid system (NLS) for the treatment of PCM through the use of in vitro and in vivo antifungal and safety tests. In vitro tests were undertaken in fungal (Paracoccidioides species) and in mammalian cells (pulmonary fibroblasts). In vivo tests were performed in an embryotoxicity model with zebrafish and in a PCM murine model.

\section{Materials and methods}

\subsection{Drugs and compound}

Amphotericin B and itraconazole were obtained commercially (Sigma-Aldrich) and dodecyl gallate (DOD) was synthesized according to Morais et al. (2010). To prepare stock solutions, the drugs and compound were solubilized in dimethylsulfoxide, DMSO (Labsynth).

\subsection{Association of dodecyl gallate with nanostructured lipid system}

The nanostructured lipid system (NLS) was prepared at the following composition: 10\% cholesterol (oil phase), 10\% mixture of polyoxyethylene (23) lauryl ether (Brij $\left.{ }^{\otimes} 35\right)$ and soybean phosphatidylcholine (Epikuron ${ }^{\circledR}$ 200) 2:1 (surfactant) and $80 \%$ phosphate-buffered saline (PBS - aqueous phase) as described by Formariz et al. (2005) and Bonifácio et al. (2015) with adaptations. The mixture was prepared in an ice bath using a sonicator (Q500 - Qsonica, Newtown,
CT, USA) with a potency of $500 \mathrm{~W}$, in discontinuous mode for $10 \mathrm{~min}$ with $30 \mathrm{~s}$ of incubation every $1 \mathrm{~min}$ during the sonication process. DOD $(5 \mathrm{mg}$ ) was associated to a previously prepared NLS $(1 \mathrm{~mL})$ with the aid of the sonicator in rod for $2 \mathrm{~min}$ under the same conditions used for the preparation of NLS.

\subsection{Characterization of the system}

The determination of the diameter of the particle and polydispersity index (PDI) of the free NLS or associated with DOD was performed using dynamic laser scattering at $20^{\circ} \mathrm{C}$. Free NLS or associated with DOD was also characterized for the zeta potential using the electrophoretic mobility. The samples were first diluted $\left(10 \mu \mathrm{L} \cdot \mathrm{mL}^{-1}\right)$ in aqueous potassium chloride $(\mathrm{KCl})$ solution. All the parameters were evaluated using a Zetasizer Nano NS instrument (Malvern Instruments, Worcestershire, UK). Three determinations of the parameters were carried out.

\subsection{Entrapment efficiency}

NLS + DOD ( $1 \mathrm{~mL})$ was centrifuged using a centrifugal filter unit (Amicon Ultra-4, PLGC Ultracel-PL Membrane, $100 \mathrm{kDa}$; EMD Millipore, Billerica, MA, USA) at $3000 \mathrm{rpm}$ for $20 \mathrm{~min}$ at $20^{\circ} \mathrm{C}$. Free drug content (F) in eluent was analyzed by spectrophotometry at $200 \mathrm{~nm}$. The sample was measured in duplicate. The encapsulation efficiency was calculated using the following equation:

$\%$ entrapment efficiency $=[(\mathrm{T}-\mathrm{F}) / \mathrm{T}] \times 100$

where, $\mathrm{T}$ is the total drug content and $\mathrm{F}$ is the free drug content

\subsection{In vitro fungal activity of dodecyl gallate associated with nanostructured lipid system}

The microdilution susceptibility test was performed as described in document M27-A3 from the Clinical and Laboratory Standards Institute, CLSI (CLSI, 2008), with some modifications (de Paula e Silva et al., 2013). P. brasiliensis S1 isolated 18 (chronic PCM/São Paulo, Brazil) and $P$. lutzii Pb01-like-strain ATCC MYA-826 (acute PCM/ Goiânia, Brazil) were maintained in Fava-Netto medium at $37^{\circ} \mathrm{C}$ for 4 days. The inoculum was prepared in PBS and further dilutions were prepared in sterile RPMI 1640 medium (Sigma-Aldrich) to get about $5 \times 10^{3}$ cells.mL ${ }^{-1}$. DOD dissolved in DMSO or associated with NLS was diluted in RPMI to obtain final concentrations of $0.015-250 \mathrm{mg} / \mathrm{L}$. AmB and itraconazole were used as control drugs. The solvent DMSO and the NLS were tested at concentrations corresponding to those of the compound. The plates were incubated with shaking $(150 \mathrm{rpm})$ at $37^{\circ} \mathrm{C}$ for $48 \mathrm{~h}$. After this period, the indicator Alamar Blue (BioSource International) was added and the plates were incubated with shaking (150 rpm) at $37^{\circ} \mathrm{C}$ for $24 \mathrm{~h}$. The absorbance was read on a microplate reader at $570-600 \mathrm{~nm}$ and the minimum inhibitory concentration (MIC) was determined. Three independent experiments were performed.

\subsection{Cytotoxicity of dodecyl gallate associated with nanostructured lipid system}

MRC5 (pulmonary fibroblasts) cell line (Banco de Células do Rio de Janeiro - BCRJ, Federal University of Rio de Janeiro, Brazil) was cultured in Dulbecco's Modified Eagle Medium (DMEM) supplemented with $10 \%$ fetal bovine serum and $2 \%$ of a solution of antibiotics. For the assay, cell suspensions were seeded into each well of a 96-well plate ( $5 \times 10^{5}$ cells per well), which was incubated for $24 \mathrm{~h}$ at $37^{\circ} \mathrm{C}$ in an atmosphere of $5 \% \mathrm{CO}_{2}$ to allow cell adhesion, obtaining at least $80 \%$ confluence. DOD dissolved in DMSO or associated with NLS at concentrations of $0.015-250 \mathrm{mg} / \mathrm{L}$ were added to the wells. The solvent DMSO and the NLS were tested at concentrations corresponding to those of the compounds. The cells were exposed to the compounds for 24 and $48 \mathrm{~h}$. Subsequently, $10 \mu \mathrm{L}$ of $0.01 \%$ resazurin (Sigma-Aldrich) 
was added and the plates were incubated for $6 \mathrm{~h}$. After incubation, the absorbance was read on a microplate reader at $570-600 \mathrm{~nm}$ and the $50 \%$ inhibitory concentration $\left(\mathrm{IC}_{50}\right)$ was determined. Three independent experiments were performed.

\subsection{Toxicity of dodecyl gallate associated with nanostructured lipid system in zebrafish embryos}

Wild type zebrafish (Danio rerio) were kept in a temperature controlled aquarium $\left(28 \pm 0.5^{\circ} \mathrm{C}\right)$ in a laboratory with a $14 \mathrm{~h} \mathrm{light} / 10 \mathrm{~h}$ dark cycle. Adult fish were placed for mating (1:1 or 1:2 or 2:1 male/ female ratio) and the embryos collected in the breeder. Embryos were washed with embryonic medium $(10 \mathrm{mM} \mathrm{NaCl}, 0.34 \mathrm{mM} \mathrm{KCl}, 0.66 \mathrm{mM}$ $\mathrm{CaCl}_{2} \cdot 2 \mathrm{H}_{2} \mathrm{O}, 0.66 \mathrm{mM} \mathrm{MgCl} 2 \cdot 6 \mathrm{H}_{2} \mathrm{O}$ ) supplemented with $0.00003 \%$ methylene blue and transferred to 96-well plates (2 embryos/well). Different concentrations of free DOD or associated with NLS were added $(0.015-125 \mathrm{mg} / \mathrm{L})$. The plates were incubated at $28{ }^{\circ} \mathrm{C}$ and malformation phenotypes such as coagulation of fertilized eggs, lack of somite formation, lack of tail detachment and lack of heart rate were observed at 5, 24, 48 and 120 hpf (OECD, 2013). Three independent experiments were performed ( 24 embryos/concentration).

\subsection{Evaluation of dodecyl gallate associated with nanostructured lipid system in mice}

The use of male Balb/c mice was approved by the Research Ethics Committee of UNESP-Araraquara (Protocol CEUA/FCF/CAr $n^{\circ} 21$ / 2013). Before and during the experiment, they were maintained in a $12 \mathrm{~h}$ light/dark cycle with ad libitum acess to water and standard rodent chow. Male Balb/c mice with 6-week-old and about $25 \mathrm{~g}$ were anesthetized intramuscularly (im) with $80 \mathrm{mg} / \mathrm{kg}$ of ketamine and $10 \mathrm{mg} /$ $\mathrm{kg}$ of xylazine. $P$. brasiliensis 18 was grown in Fava-Netto solid medium for 7 days at $37^{\circ} \mathrm{C}$. The inoculum preparation was performed in PBS and $50 \mu \mathrm{L}$ of fungal suspension with $3 \times 10^{5}$ cells was inoculated intratracheally. One day after infection, the animals were divided into six groups administered the following treatments: PBS; itraconazole $5 \mathrm{mg}$ / $\mathrm{kg} /$ day; DOD $10 \mathrm{mg} / \mathrm{kg} /$ day; NLS; NLS + DOD $10 \mathrm{mg} / \mathrm{kg} /$ day; in addition, uninfected animals treated with PBS were used as a control. The treatments were administered intraperitoneally (ip) for 20 consecutive days. At the end of the experiment, the mice were euthanized and their lungs removed for CFU count. The organ was ground in PBS with the aid of a glass Potter homogenizer and $100 \mu \mathrm{L}$ were plated in BHI solid medium supplemented with $4 \%$ fetal bovine serum, $5 \%$ filtered of Pb339 and gentamicin 40 mg.L $\mathrm{L}^{-1}$ (Granzoto et al., 2013). The plates were incubated at $37{ }^{\circ} \mathrm{C}$ for 10 days. Two independent experiments were performed, with 3-4 animals/group in each experiment.

\subsection{Animal weight and biochemical analysis}

The blood of animals was collected by cardiac puncture and centrifuged at $3500 \mathrm{rpm}$ for $10 \mathrm{~min}$ at $25^{\circ} \mathrm{C}$. The serum was analyzed for hepatic parameters, alanine aminotransferase (ALT), aspartate aminotransferase (AST) and renal parameters, urea and creatinine. These biochemical analyses were performed at the Núcleo de Atendimento à Comunidade (NAC) of the Faculty of Pharmaceutical Sciences of UNESP, Araraquara, by dry chemical analysis using Vitros 250 (Orto Clinical Diagnostics - Johnson \& Johnson Company ${ }^{\circledR}$, São Paulo, SP, Brazil). The animals were also weighed at the end of the experiment.

\subsection{Statistical analysis}

The statistical analysis of the results was performed in the Graph Pad Prisma 5 program (La Jolla, CA, USA). The survival curves were plotted by the Kaplan-Meyer method and analyzed by Log-rank (Mantel-Cox). The fungal burden and biochemical parameters were analyzed by ANOVA with Bonferroni post-test. The p value $<.05$ was
Table 1

Mean values and standard deviation of the particle sizes, PDI and zeta potential for the nanostructured lipid system (NLS), as well as for the compound dodecyl gallate associated with system (NLS + DOD).

\begin{tabular}{llll}
\hline & Size $(\mathrm{nm})$ & Polydispersity index $(\mathrm{PDI})$ & Zeta potential $(\mathrm{mV})$ \\
\hline NLS & $117.9 \pm 2.196$ & $0.153 \pm 0.002$ & $-2.610 \pm 0.300$ \\
NLS + DOD & $154.4 \pm 2.829$ & $0.255 \pm 0.008$ & $-2.731 \pm 0.310$ \\
\hline
\end{tabular}

considered statistically significant.

\section{Results}

\subsection{Properties of NLS}

As depicted in Table 1, the mean particle size of the NLS was $117.9 \pm 2.196 \mathrm{~nm}$. The association of DOD caused an increase in particle size $(154.4 \pm 2.829 \mathrm{~nm})$, which is a strong indication that the incorporation of the compound into the NLS was successful. The polydispersity index (PDI) shows the relative homogeneity between the particle sizes in the sample. The PDI presented values of $0.153 \pm 0.002$ and $0.255 \pm 0.008$ for the NLS and NLS + DOD, respectively. These data showed that the samples have homogeneity. The results of the NLS and NLS + DOD for the zeta potential showed that both presented a similar surface charge of approximately $2.7 \mathrm{mV}$. Additionally, the entrapment efficiency assay was performed and it showed that most of the DOD (99.78\%) was associated to the NLS.

\subsection{In vitro action}

Following CLSI protocols (CLSI, 2008; de Paula e Silva et al., 2013), Table 2 shows the minimum inhibitory concentration (MIC) values for DOD dissolved in DMSO or associated with NLS. The MIC of the DOD was $0.12 \mathrm{mg} / \mathrm{L}$ for both Paracoccidioides species. When incorporated into the NLS, there was an increase in the MIC value of the compound to $0.24 \mathrm{mg} / \mathrm{L}$ and $0.49 \mathrm{mg} / \mathrm{L}$ for $P$. brasiliensis and $P$. lutzii, respectively. DMSO and NLS showed no antifungal activity at the equivalent DOD concentrations. AmB had a MIC of $0.03 \mathrm{mg} / \mathrm{L}$ for both species and itraconazole presented a MIC of $0.008 \mathrm{mg} / \mathrm{L}$ for $P$. brasiliensis and $0.015 \mathrm{mg} / \mathrm{L}$ for $P$. lutzii.

An in vitro assay was also performed to address whether NLS + DOD exerted toxicity on non-fungal eukaryotic cells (lung fibroblasts). Through the Fig. 1 and the inhibitory concentration 50\% (IC 50 ) values (Table 2), it is possible to observe a toxic effect of the compound free or associated to nanoparticle more pronounced at $48 \mathrm{~h}$ compared to $24 \mathrm{~h}$ of treatment on the cells. A reduction in the viability of the cells occurs with increasing concentration of dodecyl gallate $(0.49$ to $250 \mathrm{mg} / \mathrm{L})$.

The association with NLS contributed substantially to a toxicity reduction of DOD in the lung fibroblasts, (Fig. 1, C and D). The IC 50 value of DOD increased with the incorporation to the NLS from 103.9

Table 2

Minimal inhibitory concentration (MIC) against Paracoccidioides species and inhibitory concentration 50\% in lung fibroblasts (MRC5) of free dodecyl gallate (DOD) and associated wiyh nanostructured lipid system (NLS + DOD).

\begin{tabular}{lllll}
\hline & $\begin{array}{l}\text { P. brasiliensis } \\
18 \text { MIC }(\mathrm{mg} / \mathrm{L})\end{array}$ & $\begin{array}{l}\text { P. lutzii 01 } \\
\text { MIC }(\mathrm{mg} / \\
\mathrm{L})\end{array}$ & $\begin{array}{l}\text { MRC5 cells } \\
24 \mathrm{~h}-\mathrm{IC}_{50} \\
(\mathrm{mg} / \mathrm{L})\end{array}$ & $\begin{array}{l}\text { MRC5 cells } \\
48 \mathrm{~h}-\mathrm{IC}_{50}(\mathrm{mg} / \\
\mathrm{L})\end{array}$ \\
\hline DOD & 0.12 & 0.12 & 103.9 & 63.4 \\
NLS + DOD & 0.24 & 0.49 & $>250$ & $>250$ \\
DMSO & $>250$ & $>250$ & $>250$ & $>250$ \\
NLS & $>250$ & $>250$ & $>250$ & $>250$ \\
AmB & 0.03 & 0.03 & - & - \\
ITC & 0.008 & 0.015 & - & - \\
\hline
\end{tabular}

AmB: Amphotericin B; ITC: Itraconazole. 
$24 \mathrm{~h}$

A

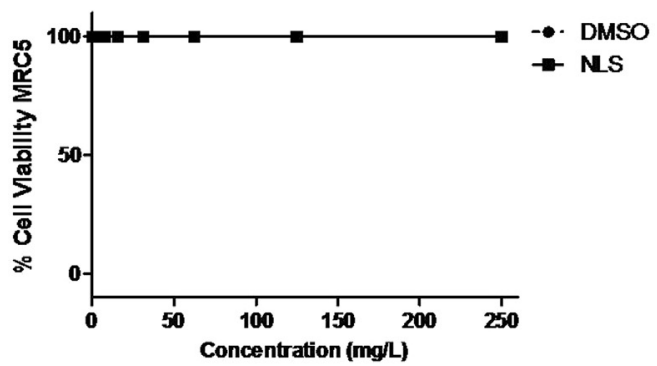

C

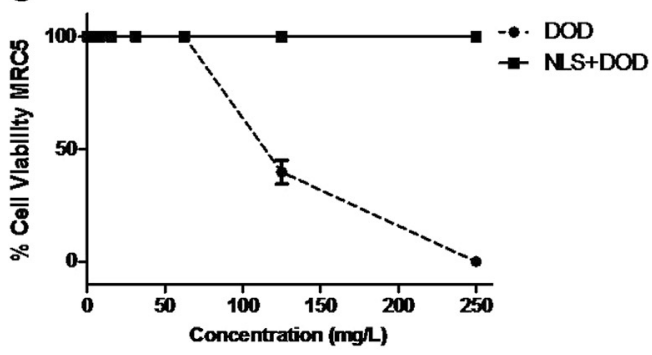

$48 \mathrm{~h}$

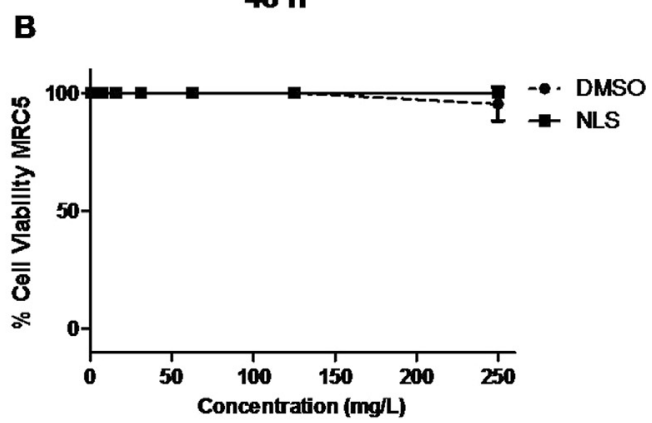

D

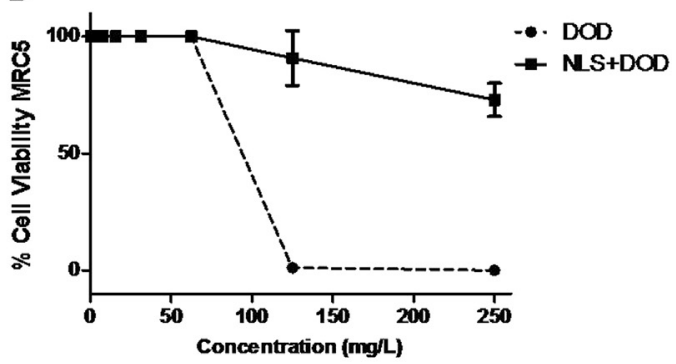

Fig. 1. Cytotoxicity of (A) the vehicle dimethylsulfoxide (DMSO); (B) the nanostructured lipid system (NLS); (C) free dodecyl gallate (DOD); and (D) DOD in association with NLS (NLS + DOD) in lung fibroblasts (MRC5).

to $>250 \mathrm{mg} / \mathrm{L}$ after $24 \mathrm{~h}$ of treatment and from 63.4 to $>250 \mathrm{mg} / \mathrm{L}$ with $48 \mathrm{~h}$ of treatment (Table 2). NLS and DMSO showed no toxic effect at the concentrations tested (Fig. $1, \mathrm{~A}$ and $\mathrm{B}$ ). Thus, the $\mathrm{IC}_{50}$ values found for the free compound and when associated with NLS in lung fibroblasts were substantially higher than the MIC values shown above.

\subsection{NLS reduces the toxicity of DOD in zebrafish embryos}

The DOD associated with NLS was also tested in zebrafish embryos at some concentrations previously used for the susceptibility and cytotoxicity tests $(0.015,0.03,0.12,0.49,1.95,7.8,31.25,62.5$ and $125 \mathrm{mg} / \mathrm{L})$. Ther toxicity was directly proportional to the concentration of the compounds (Fig. 2). The lethal concentration $50 \%\left(\mathrm{LC}_{50}\right)$ found at $120 \mathrm{hpf}$ for DOD was $16.58 \mu \mathrm{g} \cdot \mathrm{mL}^{-1}$ (Table 3). The association with NLS substantially reduced the toxicity of the compound and the $\mathrm{LC}_{50}$ was determined as $>125 \mathrm{mg} / \mathrm{L}$. The treatment with NLS alone showed no toxicity in the zebrafish embryos at the tested concentrations.

\subsection{NLS + DOD has activity against $P$. Brasiliensis in murine model}

Twenty days after the treatment of Balb/c mice, the lungs of the animals were removed and the fungal burden was determined through the consideration of weight of the organ. In Fig. 3, the mean of colonyforming unit $(\mathrm{CFU}) / \mathrm{g}$ of lung in the infected with $P$. brasiliensis 18 $(\mathrm{Pb} 18)$ and untreated animals was $2.5 \times 10^{4}$. The treatment with $5 \mathrm{mg} /$ $\mathrm{kg}$ itraconazole (ITRA) control drug significantly reduced the number of $\mathrm{CFU} / \mathrm{g}$ in the lungs to $3.6 \times 10^{3}$ (p $\left.<.05\right)$. DOD at $10 \mathrm{mg} / \mathrm{kg}$ did not reduce the mean $\mathrm{CFU} / \mathrm{g}$ in the lungs $\left(7.8 \times 10^{3}\right)$ as compared to the infected and untreated group. However, the incorporation of DOD $10 \mathrm{mg} / \mathrm{kg}$ to NLS promoted a significant reduction in the number of $\mathrm{CFU} / \mathrm{g}$ of lung $\left(4.7 \times 10^{3}, \mathrm{p}<.05\right)$. NLS also did not demonstrate antifungal activity in the murine model $\left(1.4 \times 10^{4} \mathrm{CFU} / \mathrm{g}\right.$ lung $)$.

Blood samples were collected from mice for the evaluation of toxicity parameters, ALT, AST, urea and creatinine. AST and ALT are considered biochemical indicators of liver function; their increase may represent the presence of hepatocyte lesions or liver fibrosis. Urea and creatinine are known to be related to renal function and an elevation in their levels may indicate injury or dysfunction of the kidneys. The mean of the four parameters analyzed was not altered in the group infected with $P$. brasiliensis 18 as compared to the non-infected group (control). In addition, the treatment of animals with $5 \mathrm{mg} / \mathrm{kg}$ of ITRA and $10 \mathrm{mg}$ / $\mathrm{kg}$ of DOD or NLS + DOD did not alter AST, ALT, urea and creatinine levels compared to the control group (Table 4).

The body weight of the mice, which is considered as another indicator of the in vivo toxicity of DOD or NLS + DOD, was also analyzed. The animals in all groups were weighed at the end of the experiment and no differences in mean body weight were observed (Table 4).

\section{Discussion}

Compounds present in plants have antimicrobial properties empirically recognized for centuries and scientifically proven in the last decades (Santos et al., 2016). In this context, several natural products and synthetic derivatives such as maitenine, pristimerine, curcumin, 6quinolinyl $\mathrm{N}$-oxide chalcone and ajoene showed in vitro and in vivo activity against Paracoccidioides sp. (de Sá et al., 2015; Gullo et al., 2012; Maluf et al., 2008; Martins et al., 2009). In addition, the strategy of using nanoparticles to carry commercially available antifungal agents has been explored (Gupta and Vyas, 2012; Nasti et al., 2006; Voltan et al., 2016). In the present work, we associated a nanostructured lipid system (NLS) with dodecyl gallate (DOD), an antifungal compound derived from gallic acid with low aqueous solubility, and evaluated the association for the treatment of paracoccidioidomycosis (PCM). The NLS and NLS + DOD characterization revealed that the values obtained are in the range of $10-250 \mathrm{~nm}(100-2500 \AA)$, ideal for the nanostructured lipid system (Formariz et al., 2005). In addition, the negative charge in potential zeta comes from the components of the formulations such as soybean phosphatidylcholine and cholesterol, which have free ester groups [-RCOOR'-] and a free hydroxyl group [-OH], respectively (Silva et al., 2016). In addition, NLS exhibited high entrapment efficiency, which was able to associate the most of the compound $(99.78 \%)$.

DOD effectively inhibited the growth of Paracoccidioides species and the association with NLS slightly increased the MIC values in one or two dilutions. However, the difference between the results for DOD and NLS + DOD was well within the acceptable variation for microdilution 

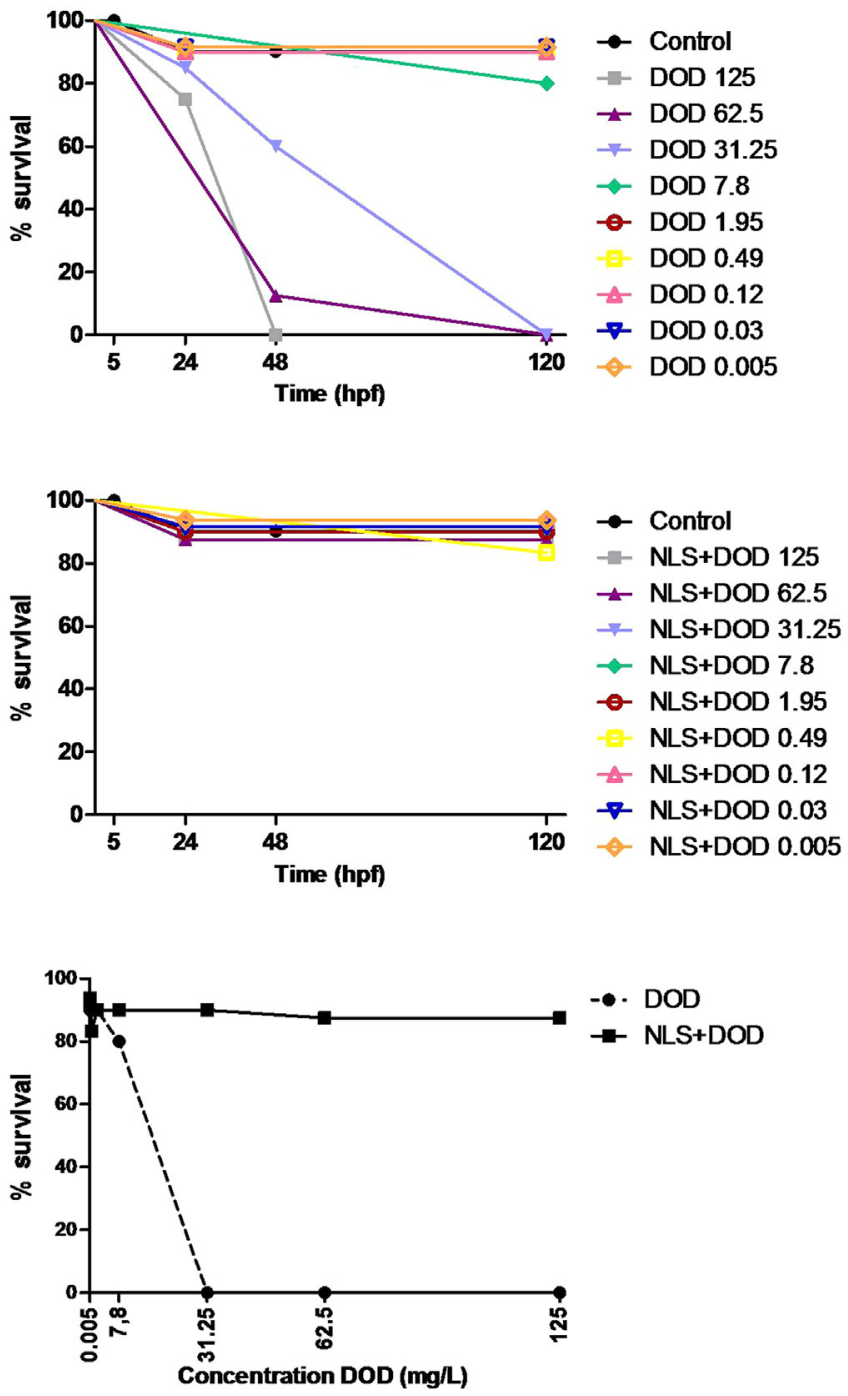

Fig. 2. Survival curve (A and B) and concentration-response curve $120 \mathrm{hpf}(\mathrm{C})$ of zebrafish embryos treated with free dodecyl gallate (DOD) and associated with nanostructured lipid system (NLS + DOD). This experiment was performed in triplicate (2 embryos/well and 24 embryos/concentration).

Table 3

Lethal concentration $50 \%$ for free dodecyl gallate (DOD) free and associated with nanostructured lipid system (NLS + DOD) in a zebrafish embryo model.

\begin{tabular}{lc}
\hline & $\mathrm{LC}_{50}(\mathrm{mg} / \mathrm{L})-120 \mathrm{hpf}$ \\
\hline DOD & 16.58 \\
NLS + DOD & $>125$ \\
DMSO & $>125$ \\
NLS & $>125$ \\
\hline
\end{tabular}

methods (Pfaller et al., 2011). The scientific literature reports a variety of effects on nanostructured lipid carriers on the in vitro antimicrobial activity. Some drugs, such as miconazole and clotrimazole, had their antifungal effect potentiated when associated with nanostructured lipid systems (Esposito et al., 2013; Mendes et al., 2013; Singh et al., 2016). On the other hand, similar to that observed in the present study, the antimicrobial activity was maintained when tetracycline and ruthenium compounds were associated with these systems (de Freitas et al., 2014; Lin et al., 2013). It may be suggested that different interactions between the drug/compound and the carrier, or between the system and the membrane of the microorganism, may influence the antifungal

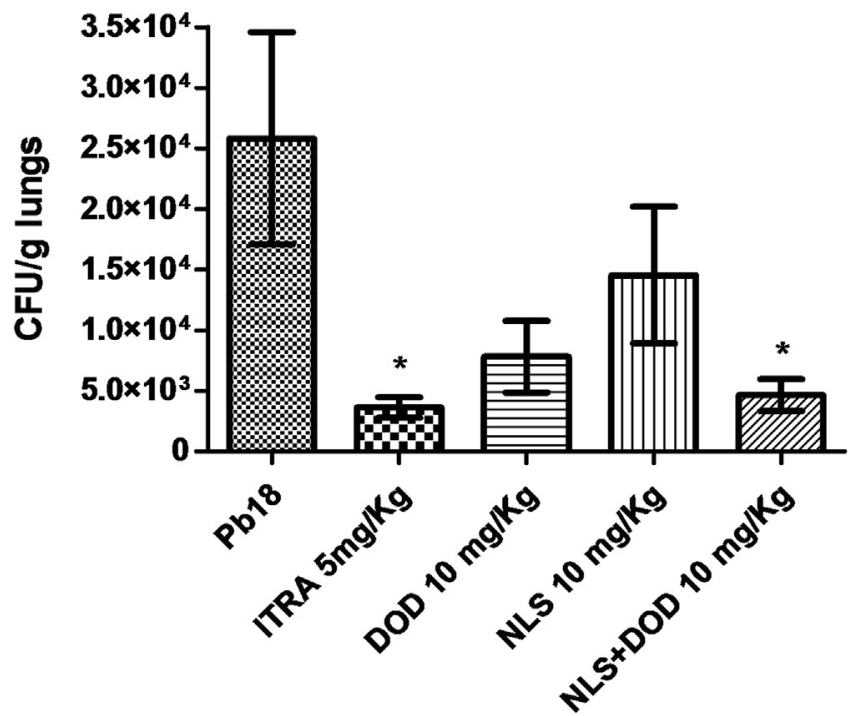

Fig. 3. Fungal lung burden of Balb/c mice infected with $P$. brasiliensis (Pb18) and treated with $5 \mathrm{mg} / \mathrm{kg}$ of ITRA, $10 \mathrm{mg} / \mathrm{kg}$ of free dodecyl gallate (DOD) and associated with nanostructured lipid system (NLS + DOD). The evaluation was done 20 days after the treatment. Data expressed as mean and standard error mean. ${ }^{*} \mathrm{P}<.05$ vs. Pb18. $\mathrm{N}=6-7 /$ group.

response.

DOD and NLS + DOD were also tested on non-fungal eukaryotic cells. The association with NLS contributed to a substantial reduction in the toxicity of DOD on the lung fibroblasts (MRC5) and the $\mathrm{IC}_{50}$ values found were substantially higher than the MIC values, which permitted a wide therapeutic window.

Zebrafish (Danio rerio) has proven useful for assessing the potential toxic effects of new compounds on embryonic development. The use of zebrafish embryos is advantageous because they are small and can readily absorb the compounds with which they are placed in contact. Other advantages include transparent embryos, which allow the visualization of their development, and the posture of a couple generates up to 200 embryos (Kanungo et al., 2014). The genome of this vertebrate has already been fully sequenced, showing that $71.4 \%$ of the zebrafish genes are orthologous with those of humans (Howe et al., 2013). Thus, although mammalian models are still considered gold standard for the study of teratogenic effects, zebrafish has been increasingly accepted as a model for predicting these effects (Kanungo et al., 2014). In this respect, the analysis of the toxicity of nanoparticles and antifungals as azole has been carried out on embryos and larvae of zebrafish individually (de Jong et al., 2011; Kanungo et al., 2014). However, the association of antifungal compound with a nanostructured lipid system has been evaluated for the first time in this work. The DOD presented $\mathrm{LC}_{50}$ values in zebrafish greater than 20 times the MIC of these compounds against Paracoccidioides sp, that is, they allow a wide therapeutic window. However, the association with the NLS allowed greater safety for the administration of the DOD $\left(\mathrm{LC}_{50} 255\right.$ times greater than MIC). The low teratogenic potential found is a great advantage for the development of NLS + DOD as new antifungal agent mainly in relation to azoles. This class of drugs has no indication to be used in pregnant women with mycoses, because it has toxic effects to the embryos, causing a variety of malformations, including craniofacial, cardiac, pulmonary, urogenital, spinal, eye and ear (de Jong et al., 2011).

Finally, we tested the DOD and NLS + DOD in conventional murine model of PCM infection. Neither treatment affected the weight of the mice or induced liver or kidney toxicity. DOD at $10 \mathrm{mg} / \mathrm{kg}$ did not reduce the fungal burden of mice lungs. However, the incorporation of DOD $10 \mathrm{mg} / \mathrm{kg}$ to the NLS showed a significant reduction in fungal burden of mice lungs compared to control group. Previous in vivo 
Table 4

Body weight and hepatic and renal parameters in the serum of mice treated with free dodecyl gallate (DOD) and associated with nanostructured lipid system (NLS + DOD). Data expressed as mean and standard error mean.

\begin{tabular}{|c|c|c|c|c|c|}
\hline Group & Body weight (g) & AST (U/L) & ALT (U/L) & Urea (mg/dL) & Creatinine $(\mathrm{mg} / \mathrm{dL})$ \\
\hline Control & $24.5 \pm 0.8$ & $199.0 \pm 38.5$ & $55.2 \pm 6.6$ & $56.6 \pm 2.8$ & $0.18 \pm 0.02$ \\
\hline Pb18 & $24.6 \pm 0.2$ & $133.3 \pm 31.5$ & $58.2 \pm 7.1$ & $61.1 \pm 2.5$ & $0.15 \pm 0.01$ \\
\hline ITRA & $24.8 \pm 0.5$ & $128.4 \pm 23.2$ & $49.6 \pm 8.0$ & $60.9 \pm 4.0$ & $0.16 \pm 0.01$ \\
\hline DOD & $23.3 \pm 0.5$ & $204.6 \pm 43.2$ & $66.4 \pm 3.6$ & $58.3 \pm 2.9$ & $0.15 \pm 0.01$ \\
\hline NLS & $24.9 \pm 0.5$ & $122.8 \pm 50.1$ & $57.8 \pm 3.6$ & $61.4 \pm 3.0$ & $0.18 \pm 0.02$ \\
\hline $\mathrm{NLS}+\mathrm{DOD}$ & $24.4 \pm 0.4$ & $210.3 \pm 67.2$ & $52.7 \pm 4.3$ & $55.8 \pm 3.0$ & $0.15 \pm 0.01$ \\
\hline
\end{tabular}

studies also used lipid nanoparticles to carry antifungal drugs. For example, Nasti et al. (2006), used a liposomal formulation to associate anti-fungal nystatin and observed an increase in survival and reduction of fungal load of mice infected with $C$. neoformans. Gupta and Vyas (2012) have shown that the burden of $C$. albicans on a cutaneous infection in mice was lower for lipid nanoparticles carrying fluconazole than free drug.

In summary, in vitro and in vivo assays were performed to evaluate the efficacy against Paracoccidioides sp. and the toxicity of the association of DOD with a NLS. DOD is soluble in alcohols, but has poor solubility in water. Therefore, we selected it for an association with a NLS. The results showed that this association was very beneficial, since it contributed to reduce the toxicity of this compound on lung fibroblasts and on the zebrafish model. This may be attributed to well known propriety of lipid nanostructured system to encapsulate lipophilic drugs/nutrients in their lipid core with a controlled release capacity. In addition, increased antifungal efficacy was observed in the murine model, which may be due to improved bioavailability of DOD from NLS. Thus, in case of NLS + DOD, the compound concentration is maintained for a prolonged time period in the serum and tissues which subsequently enhanced the therapeutic efficacy of DOD against $P$. brasiliensis in mice (Garg and Singh, 2011). Our study demonstrated that NLS is a potential as a delivery system for the use of DOD as a treatment for systemic mycosis.

\section{Declarations of interest}

None.

\section{Acknowledgments}

The authors acknowledge the excellent technical support of Rosangela Moraes da Silva, Cláudia Tavares dos Santos and Paulo César Gomes for experiments with animals and cells. This work was supported by Conselho Nacional de Pesquisa e Desenvolvimento (CNPq); Fundação de Amparo à Pesquisa do Estado de São Paulo (FAPESP) [Grant Numbers 2015/03700-9, 2014/10446-9 and 2013/10917-9] and Coordenação de Aperfeiçoamento de Pessoal de Nível Superior (CAPES).

\section{References}

Arantes, T.D., Theodoro, R.C., Teixeira, M.E.M., Bosco, S.E.M., Bagagli, E., 2016 Environmental mapping of Paracoccidioides spp. in Brazil reveals new clues into genetic diversity, biogeography and wild host association. PLoS Negl. Trop. Dis. 10 e0004606.

Bates, D.W., Yu, D.T., 2003. Clinical impact of drug-drug interactions with systemic azole antifungals. Drugs Today (Barc) 39, 801-813.

Benincasa, M., Pacor, S., Wu, W., Prato, M., Bianco, A., Gennaro, R., 2011. Antifungal activity of amphotericin B conjugated to carbon nanotubes. ACS Nano 5, 199-208.

Bocca, A.L., Amaral, A.C., Teixeira, M.M., Sato, P.K., Sato, P., Shikanai-Yasuda, M.A., Soares Felipe, M.S., 2013. Paracoccidioidomycosis: eco-epidemiology, taxonomy and clinical and therapeutic issues. Future Microbiol. 8, 1177-1191.

Bonifácio, B.V., Ramos, M.A., da Silva, P.B., Negri, K.M., de Oliveira Lopes, É., de Souza, L.P., Vilegas, W., Pavan, F.R., Chorilli, M., Bauab, T.M., 2015. Nanostructured lipid system as a strategy to improve the anti-Candida albicans activity of Astronium sp. Int. J. Nanomed. 10, 5081-5092.
Botero Aguirre, J.P., Restrepo Hamid, A.M., 2015. Amphotericin B deoxycholate versus liposomal amphotericin B: effects on kidney function. Cochrane Database Syst. Rev CD010481.

Bunjes, H., 2010. Lipid nanoparticles for the delivery of poorly water-soluble drugs. J. Pharm. Pharmacol. 62, 1637-1645.

Chaudhari, M.B., Desai, P.P., Patel, P.A., Patravale, V.B., 2016. Solid lipid nanoparticles of amphotericin B (AmbiOnp): in vitro and in vivo assessment towards safe and effective oral treatment module. Drug Deliv. Transl Res 6, 354-364.

Choubey, S., Varughese, L.R., Kumar, V., Beniwal, V., 2015. Medicinal importance of gallic acid and its ester derivatives: a patent review. Pharm. Pat. Anal. 4, 305-315.

CLSI, 2008. Reference method for broth dilution antifungal susceptibility testing of yeasts; aproved standard - third edition. CLSI document M27-A3 (ISBN-1-56238-6662). Clinical and Laboratory Standards Institute, Wayne, PA, USA.

de Freitas, E.S., da Silva, P.B., Chorilli, M., Batista, A.A., de Oliveira Lopes, E., da Silva, M.M., Leite, C.Q., Pavan, F.R., 2014. Nanostructured lipid systems as a strategy to improve the in vitro cytotoxicity of ruthenium(II) compounds. Molecules 19, 5999-6008.

de Jong, E., Barenys, M., Hermsen, S.A., Verhoef, A., Ossendorp, B.C., Bessems, J.G., Piersma, A.H., 2011. Comparison of the mouse embryonic stem cell test, the rat whole embryo culture and the zebrafish embryotoxicity test as alternative methods for developmental toxicity testing of six 1,2,4-triazoles. Toxicol. Appl. Pharmacol. 253, 103-111.

de Paula E Silva, A.C., Costa-Orlandi, C.B., Gullo, F.P., Sangalli-Leite, F., de Oliveira, H.C., da Silva, J.E.F., Scorzoni, L., Pitangui, N.E.S., Rossi, S.A., Benaducci, T., Wolf, V.G., Regasini, L.O., Petrônio, M.S., Silva, D.H., Bolzani, V.S., Fusco-Almeida, A.M., Mendes-Giannini, M.J., 2014. Antifungal activity, of decyl gallate against several species of pathogenic fungi. Evid. Based Complement Alternat. Med. 2014, 506273.

de Paula e Silva, A.C., Oliveira, H.C., Silva, J.F., Sangalli-Leite, F., Scorzoni, L., FuscoAlmeida, A.M., Mendes-Giannini, M.J., 2013. Microplate alamarBlue assay for Paracoccidioides susceptibility testing. J. Clin. Microbiol. 51, 1250-1252.

de Sá, N.P., Cisalpino, P.S., Tavares, L.E.C., Espíndola, L., Pizzolatti, M.G., Santos, P.C., de Paula, T.P., Rosa, C.A., de Souza, D.A.G., Santos, D.A., Johann, S., 2015. Antifungal activity of 6-quinolinyl N-oxide chalcones against Paracoccidioides. J. Antimicrob. Chemother. 70, 841-845.

Derengowski, L.S., De-Souza-Silva, C., Braz, S.V., Mello-De-Sousa, T.M., Báo, S.N., Kyaw, C.M., Silva-Pereira, I., 2009. Antimicrobial effect of farnesol, a Candida albicans quorum sensing molecule, on Paracoccidioides brasiliensis growth and morphogenesis. Ann. Clin. Microbiol. Antimicrob. 8, 13.

Esposito, E., Ravani, L., Contado, C., Costenaro, A., Drechsler, M., Rossi, D., Menegatti, E., Grandini, A., Cortesi, R., 2013. Clotrimazole nanoparticle gel for mucosal administration. Mater. Sci. Eng. C Mater. Biol. Appl. 33, 411-418.

Formariz, T.P., Urban, M.C.C., Silva Junior, A.A., Gremião, M.P.D., Oliveira, A.G. 2005. Microemulsões e fases líquidas cristalinas como sistemas de liberação de fármacos. Rev. Bras Cienc. Farm 301-313.

Garg, A., Singh, S., 2011. Enhancement in antifungal activity of eugenol in immunosuppressed rats through lipid nanocarriers. Colloids Surf. B Biointerfaces 87 280-288.

Granzoto, D.S., Vitali, L.H., Martinez, R., 2013. Efficacy of voriconazole in experimental rat paracoccidioidomycosis. Rev, Soc. Bras Med. Trop. 46, 79-83.

Gullo, F.P., Sardi, J.C., Santos, V.A., Sangalli-Leite, F., Pitangui, N.S., Rossi, S.A., de Paula, E., Silva, A.C., Soares, L.A., Silva, J.F., Oliveira, H.C., Furlan, M., Silva, D.H., Bolzani, V.S., Mendes-Giannini, M.J., Fusco-Almeida, A.M., 2012. Antifungal activity of maytenin and pristimerin. Evid. Based Complement Alternat. Med. 2012, 340787.

Gupta, M., Vyas, S.P., 2012. Development, characterization and in vivo assessment of effective lipidic nanoparticles for dermal delivery of fluconazole against cutaneous candidiasis. Chem. Phys. Lipids 165, 454-461.

Hahn, R.C., Fontes, C.J., Batista, R.D., Hamdan, J.S., 2002. In vitro comparison of activities of terbinafine and itraconazole against Paracoccidioides brasiliensis. J. Clin. Microbiol 40, 2828-2831.

Hahn, R.C., Morato Conceição, Y.T., Santos, N.L., Ferreira, J.F., Hamdan, J.S., 2003. Disseminated paracoccidioidomycosis: correlation between clinical and in vitro resistance to ketoconazole and trimethoprim sulphamethoxazole. Mycoses 46, 342-347.

Howe, K., Clark, M.D., Torroja, C.F., Torrance, J., Berthelot, C., Muffato, M., Collins, J.E., Humphray, S., McLaren, K., Matthews, L., McLaren, S., Sealy, I., Caccamo, M., Churcher, C., Scott, C., Barrett, J.C., Koch, R., Rauch, G.J., White, S., Chow, W., Kilian, B., Quintais, L.T., Guerra-Assunção, J.A., Zhou, Y., Gu, Y., Yen, J., Vogel, J.H., Eyre, T., Redmond, S., Banerjee, R., Chi, J., Fu, B., Langley, E., Maguire, S.F., Laird, G.K., Lloyd, D., Kenyon, E., Donaldson, S., Sehra, H., Almeida-King, J., Loveland, J., Trevanion, S., Jones, M., Quail, M., Willey, D., Hunt, A., Burton, J., Sims, S., McLay, K., Plumb, B., Davis, J., Clee, C., Oliver, K., Clark, R., Riddle, C., Elliot, D., Eliott, D., 
Threadgold, G., Harden, G., Ware, D., Begum, S., Mortimore, B., Mortimer, B., Kerry, G., Heath, P., Phillimore, B., Tracey, A., Corby, N., Dunn, M., Johnson, C., Wood, J., Clark, S., Pelan, S., Griffiths, G., Smith, M., Glithero, R., Howden, P., Barker, N., Lloyd, C., Stevens, C., Harley, J., Holt, K., Panagiotidis, G., Lovell, J., Beasley, H., Henderson, C., Gordon, D., Auger, K., Wright, D., Collins, J., Raisen, C., Dyer, L., Leung, K., Robertson, L., Ambridge, K., Leongamornlert, D., McGuire, S., Gilderthorp, R., Griffiths, C., Manthravadi, D., Nichol, S., Barker, G., Whitehead, S., Kay, M., Brown, J., Murnane, C., Gray, E., Humphries, M., Sycamore, N., Barker, D., Saunders, D., Wallis, J., Babbage, A., Hammond, S., Mashreghi-Mohammadi, M., Barr, L., Martin, S., Wray, P., Ellington, A., Matthews, N., Ellwood, M., Woodmansey, R., Clark, G., Cooper, J., Tromans, A., Grafham, D., Skuce, C., Pandian, R., Andrews, R., Harrison, E., Kimberley, A., Garnett, J., Fosker, N., Hall, R., Garner, P., Kelly, D., Bird, C., Palmer, S., Gehring, I., Berger, A., Dooley, C.M., Ersan-Ürün, Z., Eser, C., Geiger, H., Geisler, M., Karotki, L., Kirn, A., Konantz, J., Konantz, M., Oberländer, M., Rudolph-Geiger, S., Teucke, M., Lanz, C., Raddatz, G., Osoegawa, K., Zhu, B., Rapp, A., Widaa, S., Langford, C., Yang, F., Schuster, S.C., Carter, N.P., Harrow, J., Ning, Z., Herrero, J., Searle, S.M., Enright, A., Geisler, R., Plasterk, R.H., Lee, C., Westerfield, M., de Jong, P.J., Zon, L.I., Postlethwait, J.H., Nüsslein-Volhard, C., Hubbard, T.J., Roest Crollius, H., Rogers, J., Stemple, D.L., 2013. The zebrafish reference genome sequence and its relationship to the human genome. Nature 496, 498-503.

Kanungo, J., Cuevas, E., Ali, S.F., Paule, M.G., 2014. Zebrafish model in drug safety assessment. Curr. Pharm. Des. 20, 5416-5429.

Kauffman, C.A., 2006. Fungal infections. Proc. Am. Thorac. Soc. 3, 35-40.

Lacaz, C.S., 1994. Paracoccidioides Brasiliensis: Morphology; Evolutionary Cycle; Maitenance During Saprophytic Life; Biology; Virulence; Taxonom. CRC Press, Boca Raton.

Lin, C.H., Fang, Y.P., Al-Suwayeh, S.A., Yang, S.Y., Fang, J.Y., 2013. Percutaneous absorption and antibacterial activities of lipid nanocarriers loaded with dual drugs for acne treatment. Biol. Pharm. Bull. 36, 276-286.

Maluf, M.L., Takahachi, G., Svidzinski, T.I., Xander, P., Apitz-Castro, R., Bersani-Amado, C.A., Cuman, R.K., 2008. Antifungal activity of ajoene on experimental murine paracoccidioidomycosis. Rev. Iberoam Micol. 25, 163-166.

Martins, C.V., da Silva, D.L., Neres, A.T., Magalhães, T.F., Watanabe, G.A., Modolo, L.V., Sabino, A.A., de Fátima, A., de Resende, M.A., 2009. Curcumin as a promising antifungal of clinical interest. J. Antimicrob. Chemother. 63, 337-339.

Marwaha, R.K., Maheshwari, A., 1999. Systemic antifungal therapy in pediatric practice. Indian Pediatr. 36, 1011-1021.

Mendes, A.I., Silva, A.C., Catita, J.A., Cerqueira, F., Gabriel, C., Lopes, C.M., 2013. Miconazole-loaded nanostructured lipid carriers (NLC) for local delivery to the oral mucosa: improving antifungal activity. Colloids Surf. B Biointerfaces 111, 755-763.

Mistro, S., Maciel, I.E.M., de Menezes, R.G., Maia, Z.P., Schooley, R.T., Badaró, R., 2012. Does lipid emulsion reduce amphotericin B nephrotoxicity? a systematic review and meta-analysis. Clin. Infect Dis. 54, 1774-1777.

Moen, M.D., Lyseng-Williamson, K.A., Scott, L.J., 2009. Liposomal amphotericin B: a review of its use as empirical therapy in febrile neutropenia and in the treatment of invasive fungal infections. Drugs 69, 361-392.

Morais, M.C., Luqman, S., Kondratyuk, T.P., Petronio, M.S., Regasini, L.O., Silva, D.H.,
Bolzani, V.S., Soares, C.P., Pezzuto, J.M., 2010. Suppression of TNF- $\alpha$ induced NFкB activity by gallic acid and its semi-synthetic esters: possible role in cancer chemoprevention. Nat. Prod. Res. 24, 1758-1765.

Nasti, T.H., Khan, M.A., Owais, M., 2006. Enhanced efficacy of pH-sensitive nystatin liposomes against Cryptococcus neoformans in murine model. J. Antimicrob. Chemother. 57, 349-352.

OECD, 2013. Guideline for Testing of Chemicals, 236. Fish Embryo Acute Toxicity (FET) Test, OECD, Paris, France.

Ostrosky-Zeichner, L., Casadevall, A., Galgiani, J.N., Odds, F.C., Rex, J.H., 2010. An insight into the antifungal pipeline: selected new molecules and beyond. Nat. Rev. Drug Discov. 9, 719-727.

Petrikkos, G., Skiada, A., 2007. Recent advances in antifungal chemotherapy. Int. J. Antimicrob. Agents 30, 108-117.

Pfaller, M.A., Espinel-Ingroff, A., Boyken, L., Hollis, R.J., Kroeger, J., Messer, S.A., Tendolkar, S., Diekema, D.J., 2011. Comparison of the broth microdilution (BMD) method of the European Committee on Antimicrobial Susceptibility Testing with the 24-hour CLSI BMD method for testing susceptibility of Candida species to fluconazole, posaconazole, and voriconazole by use of epidemiological cutoff values. J. Clin. Microbiol. 49, 845-850.

Rang, H.P., Dale, M.M., 2007. Farmacologia, 6ed. Elsevier, Rio de Janeiro.

Santos, L.C., Furlan, M., Amorim, M.R., 2016. Produtos naturais bioativos. Cultura Acadêmica, São Paulo.

Scorzoni, L., de Paula, E., Silva, A.C., Marcos, C.M., Assato, P.A., de Melo, W.C., de Oliveira, H.C., Costa-Orlandi, C.B., Mendes-Giannini, M.J., Fusco-Almeida, A.M., 2017. Antifungal therapy: new advances in the understanding and treatment of mycosis. Front. Microbiol. 8, 36.

Shikanai-Yasuda, M.A., Telles Filho, F.E.Q., Mendes, R.P., Colombo, A.L., Moretti, M.L., 2006. Guidelines in paracoccidioidomycosis. Rev. Soc. Bras Med. Trop. 39, 297-310.

Silva, P.B., Souza, P.C., Calixto, G.M., Lopes, E.E.O., Frem, R.C., Netto, A.V., Mauro, A.E., Pavan, F.R., Chorilli, M., 2016. In vitro activity of copper(II) complexes, loaded or unloaded into a nanostructured lipid system, against mycobacterium tuberculosis. Int J. Mol. Sci. 17.

Singh, S., Singh, M., Tripathi, C.B., Arya, M., Saraf, S.A., 2016. Development and evaluation of ultra-small nanostructured lipid carriers: novel topical delivery system for athlete's foot. Drug Deliv. Transl. Res. 6, 38-47.

Thakkar, H.P., Khunt, A., Dhande, R.D., Patel, A.A., 2015. Formulation and evaluation of Itraconazole nanoemulsion for enhanced oral bioavailability. J. Microencapsul 32, $559-569$.

Verma, R.K., Pandya, S., Misra, A., 2011. Loading and release of amphotericin-B from biodegradable poly(lactic-co-glycolic acid) nanoparticles. J. Biomed. Nanotechnol. 7 , 118-120.

Volmer, A.A., Szpilman, A.M., Carreira, E.M., 2010. Synthesis and biological evaluation of amphotericin B derivatives. Nat. Prod. Rep. 27, 1329-1349.

Voltan, A.R., Quindós, G., Alarcón, K.P., Fusco-Almeida, A.M., Mendes-Giannini, M.J., Chorilli, M., 2016. Fungal diseases: could nanostructured drug delivery systems be a novel paradigm for therapy? Int. J. Nanomed. 11, 3715-3730. 